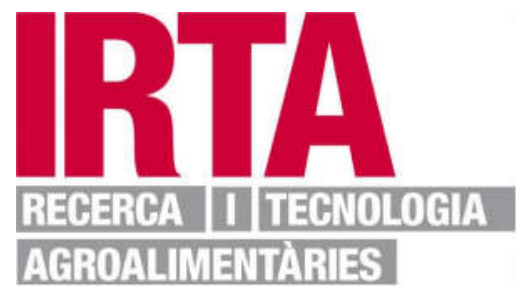

This is a post-peer-review, pre-copyedit version of an article published in Parasitology Research. The final authenticated version is available online at: https://doi.org/10.1007/s00436-017-5705-6 


\section{Toxoplasma gondii in sympatric domestic and wild ungulates in the Mediterranean ecosystem}

S. Almería, 1凶,2

Email: maria.almeria@fda.hhs.gov AQ1

O. Cabezón, 1,3

J. Paniagua, 4

D. Cano-Terriza, 4

S. Jiménez-Ruiz, 4

A. Arenas-Montes, 4

J. P. Dubey, 5

I. García-Bocanegra, 4

1 UAB, Centre de Recerca en Sanitat Animal (CReSA, IRTAUAB), Campus de la Universitat Autònoma de Barcelona, Bellaterra, Spain

2 Present Address: FDA, CFSAN, OARSA, DFEM AQ2 , Laurel, USA

3 Servei d'Ecopatologia de Fauna Salvatge (SEFaS), Departament de Medicina i Cirurgia Animals, Universitat Autònoma de Barcelona, Bellaterra, Spain

4 Departamento de Sanidad Animal, Facultad de Veterinaria, Universidad de Córdoba (UCO), Campus Universitario de Rabanales, Córdoba, Spain 
5 Animal Parasitic Diseases Laboratory, Beltsville Agricultural Research Center, Agriculture Research Service, United States Department of Agriculture, Beltsville, USA

\section{Received: 22 October 2017 / Accepted: 29 November 2017}

\section{Abstract}

Toxoplasma gondii is a zoonotic protozoan of worldwide distribution. The present study provides information on risk factors affecting $T$. gondii infection in domestic and free-ranging wild ungulates sharing habitats in Mediterranean ecosystems in Spain. Serum samples from 482 extensively reared domestic ruminants and 2351 wild ungulates were tested for $T$. gondii antibodies using the modified agglutination test (MAT, cut-off 1:25). Toxoplasma gondii seroprevalence was $41.2 \%$ of 194 sheep, $18.6 \%$ of 199 cattle and $5.6 \%$ of 89 goats. The main risk factors associated with infection in livestock were the presence of cats, feeding on the ground and at stubble fields. In wild ungulates, T. gondii antibodies were detected in $10.5 \%$ of 1063 red deer, $15.6 \%$ of 294 fallow deer, 5.6\% of 216 European mouflon, 5.6\% of 90 Spanish ibex, $13.6 \%$ of 22 roe deer and $18.6 \%$ of 666 wild boars. The risk factors affecting $T$. gondii infection in wildlife were species, age and hunting season. Significantly higher seroprevalence was found in domestic ruminants, particularly in sheep, compared to the wild species tested. The present study indicates widespread exposure to $T$. gondii among domestic and wild ungulates in Southern Spain, with significant differences among species sharing the same ecosystem. The high seroprevalence observed in domestic ruminants, particularly in sheep, reinforces the need for farm management practices to control the risk factors associated with $T$. gondii infection in extensively reared livestock. Consumption of raw and undercooked food products from domestic and wildlife species may have important implications for public health. 


\section{Keywords}

\section{Toxoplasma gondii}

Domestic ruminants

Wild ungulates

Spain

Section Editor: Larissa Howe

\section{Introduction}

AQ3

Toxoplasma gondii is a zoonotic protozoan with an indirect cycle with domestic and wild felines as definitive hosts (DH), and all warm-blooded species as intermediate hosts including human beings. One third of the human population worldwide is estimated to be infected by this parasite (Montoya and Liesenfeld 2004). Toxoplasma gondii is a food-borne pathogen (EFSA 2007). Consumption of raw or undercooked meat products containing tissues cysts is the major risk factor associated with human toxoplasmosis (Cook et al. 2000). Although T. gondii infection in human is usually asymptomatic, it can have fatal consequences in immunosuppressed people and pregnant women (Dubey 2010). Toxoplasmosis is also considered an occupational disease for abattoir workers, butchers and hunters who may become infected during evisceration and handling of meat (EFSA 2007).

Toxoplasma gondii has been isolated from different domestic and wild ungulate species worldwide (reviewed by Dubey 2010). Toxoplasmosis generates severe economic losses in livestock, being one of the major causes of abortion, foetal malformations, pre-term deliveries and stillbirths in sheep and goats. Moreover, the European Food Safety Agency identified the meat of large-game species as an important zoonotic source for $T$. gondii infection (EFSA 2007). Spain is the first and third country in Europe in the number of hunted red deer and wild boars per year, respectively (Apollonio et al. 2010). Over 133,000 red deer (Cervus elaphus) and 221,000 wild boars (Sus scrofa) are hunted annually in this 
country (MAPAMA 2016). Game meat and product are not only consumed in this country, but also around 850 tons are exported annually to other European countries (SSCCC 2009). Previous studies have shown widespread distribution of $T$. gondii in domestic and wild ungulates in Spain, reporting a high heterogeneity in the presence of the parasite depending on the geographic area (García-Bocanegra et al. 2013; Gauss et al. 2005, 2006; Calero-Bernal et al. 2016; San Miguel et al. 2016). However, few studies have assessed the presence of this parasite in domestic and wild species that share the same habitat (Panadero et al. 2010), preventing the determination of the factors that influence the parasite epidemiology in the livestock and wildlife interface. The aim of the present study was to determine the risk factors associated with the $T$. gondii infection in sympatric domestic and free-ranging large-game ungulates from Mediterranean ecosystems in Southern Spain destined for human consumption.

\section{Materials and methods}

All samples from wild ungulates were collected from legally hunted animals, by authorised hunters with the correct permits and licences and with the permission of landowners. Animals were sampled during the hunting season under Spanish and EU legislation. No animals were specifically hunted for this study and ethical approval by an Institutional Animal Care and Use Committee was not deemed necessary. The collection of blood samples from domestic ruminants was part of the official Animal Health Campaigns of Regional Government of Andalusia, Spain.

A total of 2351 wild ungulates were sampled in 101 hunting estates from Southern Spain (Fig. 1), during the hunting seasons 2011-2012 and 2015 -2016 . Blood samples were collected from hunted red deer $(n=1063)$, wild boar $(n=666)$, fallow deer (Dama dama, $n=294)$, European mouflon (Ovis aries, $n=216$ ), Spanish ibex (Capra pyrenaica hispanica, $n=90$ ) and roe deer (Capreolus capreolus, $n=22$ ) (Table 1). Samples were obtained from the thoracic cavity or by endocranial venous sinuses puncture (Arenas-Montes et al. 2013; Jiménez-Ruiz et al. 2016). 


\section{Fig. 1}

Geographic distribution of the hunting states and farms tested, and results obtained for the presence of Toxoplasma gondii antibodies in Southern Spain. a Black and grey spots indicate positive and negative hunting areas for the presence of $T$. gondii, respectively. b Black and grey areas indicate positive and negative hunting areas (polygons) and farms (squares) for the presence of $T$. gondii, respectively. The size of squares represents seroprevalence levels in the farms sampled AQ4 


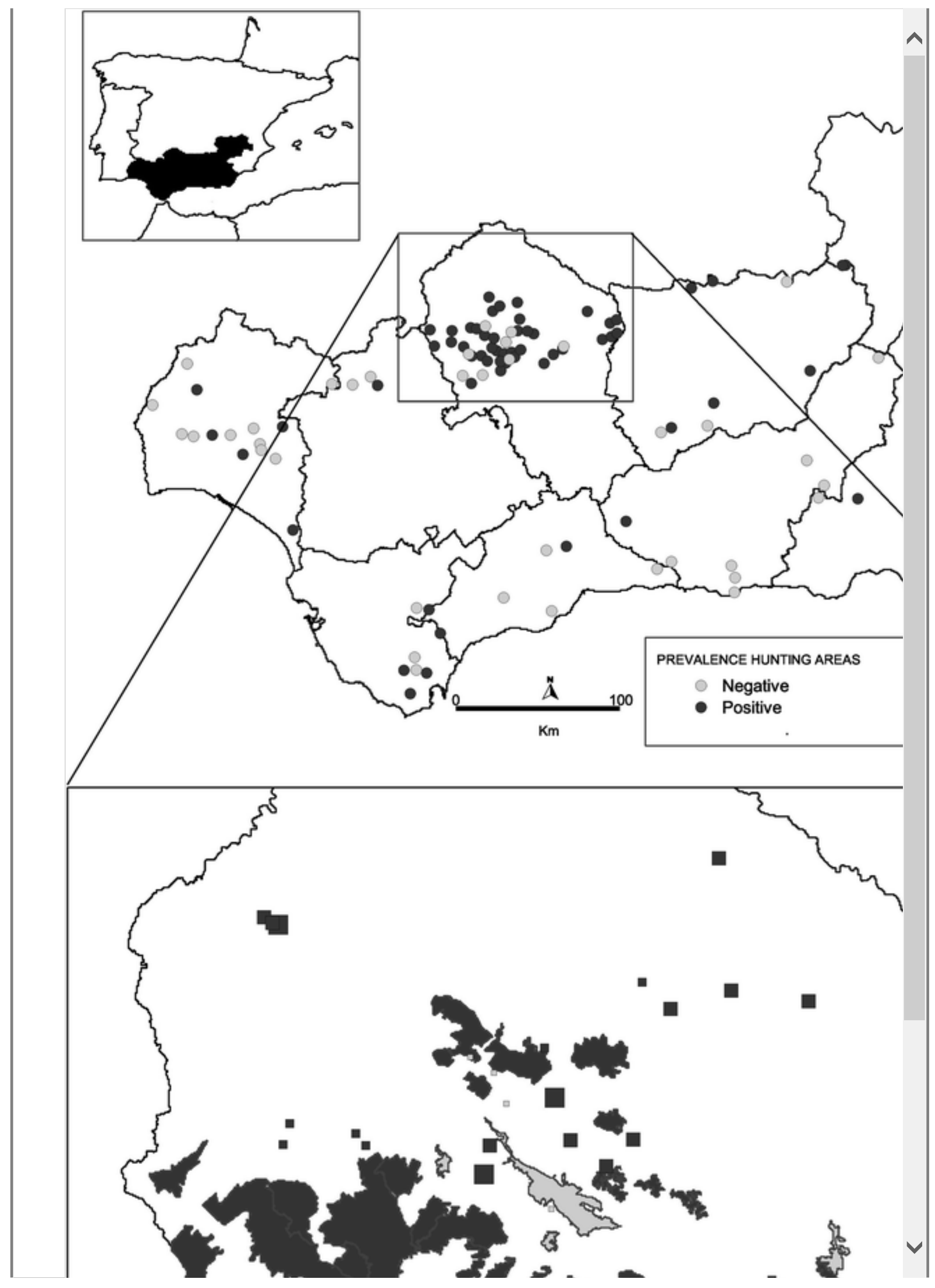


Table 1
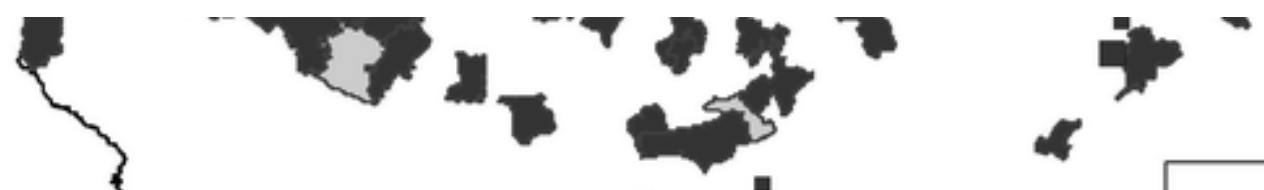

Toxoplasma gonditi

(cattle, sheep and goat) a deer, fallow deer, European moffon, Spanish ibex, roe deer and wild boar) analysedd19.9\% in Andalusia regions AQ5
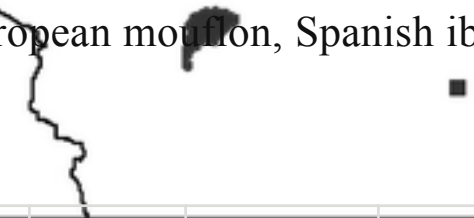

tres $(1: 25$ to $\geq 1$ :

4

0) in livestock PREV/

HERDS Nedgative

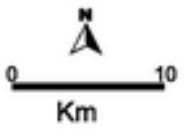

$20-49.9 \%$

$50-100 \%$

\begin{tabular}{|c|c|c|c|c|c|c|c|c|}
\hline \multirow{2}{*}{ Host } & \multirow{2}{*}{ Area } & \multirow{2}{*}{$\begin{array}{l}\text { No. } \\
\text { tested }\end{array}$} & \multirow{2}{*}{$\begin{array}{l}\text { No. } \\
\text { positive }\end{array}$} & \multirow{2}{*}{$\begin{array}{c}\% \\
\text { positive }\end{array}$} & \multicolumn{4}{|c|}{$\begin{array}{l}\text { No. of animals with MAT } \\
\text { titres }\end{array}$} \\
\hline & & & & & $1: 25$ & $1: 50$ & $1: 100$ & $\begin{array}{c}\geq \\
1: 500\end{array}$ \\
\hline Cattle & Córdoba & 199 & 37 & 18.6 & 27 & 6 & 3 & 1 \\
\hline Sheep & Córdoba & 194 & 80 & 41.2 & 8 & 3 & 40 & 29 \\
\hline Goat & Córdoba & 89 & 5 & 5.6 & 4 & & & 1 \\
\hline $\begin{array}{l}\text { Total } \\
\text { livestock }\end{array}$ & & 482 & 122 & 25.3 & 39 & 9 & 43 & 31 \\
\hline \multirow{3}{*}{ Red deer } & Córdoba & 676 & 73 & 10.8 & 31 & 23 & 15 & 4 \\
\hline & $\begin{array}{l}\text { Other } \\
\text { areas }\end{array}$ & 387 & 39 & 10.1 & 16 & 22 & 1 & \\
\hline & Total & 1063 & 112 & 10.5 & 47 & 45 & 16 & 4 \\
\hline \multirow{3}{*}{$\begin{array}{l}\text { Fallow } \\
\text { deer }\end{array}$} & Córdoba & 201 & 30 & 14.9 & 16 & 10 & 4 & \\
\hline & $\begin{array}{l}\text { Other } \\
\text { areas }\end{array}$ & 93 & 16 & 17.2 & 12 & 2 & 2 & \\
\hline & Total & 294 & 46 & 15.6 & 28 & 12 & 6 & \\
\hline \multirow{3}{*}{ Mouflon } & Córdoba & 178 & 10 & 5.6 & 6 & & 4 & \\
\hline & $\begin{array}{l}\text { Other } \\
\text { areas }\end{array}$ & 38 & 2 & 5.3 & & 2 & & \\
\hline & Total & 216 & 12 & 5.6 & 6 & 2 & 4 & \\
\hline $\begin{array}{l}\text { Spanish } \\
\text { ibex }\end{array}$ & $\begin{array}{l}\text { Other } \\
\text { areas }\end{array}$ & 90 & 5 & 5.6 & 0 & 5 & & \\
\hline Roe deer & $\begin{array}{l}\text { Other } \\
\text { areas }\end{array}$ & 22 & 3 & 13.6 & 1 & 2 & & \\
\hline
\end{tabular}




\begin{tabular}{|c|c|c|c|c|c|c|c|c|}
\hline \multirow{2}{*}{ Host } & \multirow{2}{*}{ Area } & \multirow{2}{*}{$\begin{array}{l}\text { No. } \\
\text { tested }\end{array}$} & \multirow{2}{*}{$\begin{array}{l}\text { No. } \\
\text { positive }\end{array}$} & \multirow{2}{*}{$\begin{array}{c}\% \\
\text { positive }\end{array}$} & \multicolumn{4}{|c|}{$\begin{array}{c}\text { No. of animals with MAT } \\
\text { titres }\end{array}$} \\
\hline & & & & & $1: 25$ & $1: 50$ & $1: 100$ & $\begin{array}{c}\geq \\
1: 500\end{array}$ \\
\hline \multirow{3}{*}{$\begin{array}{l}\text { Wild } \\
\text { boar }\end{array}$} & Córdoba & 604 & 115 & 19.4 & 37 & 49 & 25 & 4 \\
\hline & $\begin{array}{l}\text { Other } \\
\text { areas }\end{array}$ & 62 & 9 & 14.5 & 4 & 2 & 3 & \\
\hline & Total & 666 & 124 & 18.6 & 41 & 51 & 28 & 4 \\
\hline $\begin{array}{l}\text { Total } \\
\text { wildlife }\end{array}$ & & 2351 & 302 & 12.8 & 123 & 117 & 54 & 8 \\
\hline
\end{tabular}

The number of domestic ruminant samples collected was based on an estimated prevalence of $50 \%$ (which provides the highest sample size in studies with unknown prevalence) and the large population of domestic ruminants in Córdoba Province $(n>10,000)$ with precision set at $\pm 5 \%$ and confidence level at $95 \%(95 \% \mathrm{CI})$. These calculations resulted in a total of 385 animals to be sampled. A total of 482 domestic ruminants were finally selected using a convenience sampling according to the proportion of domestic ruminant herds present in the studied hunting areas. Therefore, blood samples from 482 extensively reared domestic ruminants, including 199 cattle, 194 sheep and 89 goats, were collected from 29 farms during 2013 , in herds with close proximity or sharing grazing areas to the hunting areas where the wild ungulates were sampled (Fig. 1). The animals were classified into three age groups based on tooth replacement: yearlings ( $<$ 1 year old), subadults ( 1 to 2 years old) and adults ( $>2$ years old) (Sáenz de Buruaga et al. 2001).

Blood samples were centrifuged at $400 \times \mathrm{g}$ for $15 \mathrm{~min}$ and sera were stored at $-20{ }^{\circ} \mathrm{C}$ until analysis. Serum samples were tested for antibodies against $T$. gondii by the modified agglutination test (MAT) (Dubey and Desmonts 1987). Sera were tested at 1:25, 1:50,1:100 and 1:500 dilutions. Sera with titres of 1:25 or higher were considered positive. MAT has been used extensively for the diagnosis of toxoplasmosis in both domestic and wildlife species (reviewed by Dubey 2010). 
The prevalence of antibodies against $T$. gondii was estimated from the ratio of positive samples to the total number of samples tested, with the exact binomial confidence intervals of $95 \%$ (95\% CI). Epidemiological information related to the sampled animals, sampling site habitat, management, biosecurity measures and environmental data were collected by direct interview with farmers and gamekeepers at each sampling site to obtain information on exposure levels to potential risk factors. A risk factors analysis was conducted in the province of Córdoba, the region with the most homogeneous sampling in wild ungulates and where domestic ruminants were sampled. A chi-square and Fisher's exact test were used to test the relevance of the explanatory variables in the risk of an animal being exposed to $T$. gondii. Covariates correlated with a $P$ value $<0.10$ in the bivariate analysis variable in each test were included from further analysis. Biologically plausible confounding factors were assessed using Mantel-Haenszel analysis and confounding was considered to be potentially significant if odd ratios (ORs) shifted appreciably (>30\%). Finally, a multiple logistic regression analysis (Hosmer and Lemeshow 2000) was performed including risk factors potentially associated with $T$. gondii exposure (likelihood-ratio Wald's test, $P<0.05$ ). The goodness of fit was assessed using the Hosmer-Lemeshow goodness-of-fit test. SPSS 22.0 software (IBM Corp., Armonk, NY, USA) was used for statistical analyses.

\section{Results}

Antibodies against $T$. gondii were detected in $41.2 \%$ of the sheep (95\% CI $34.3-48.2), 18.6 \%$ of the cattle (95\% CI 13.2-24.0) and $5.6 \%$ of the goats (95\% CI 0.8-10.4) (Table 1). The overall herd prevalence of antibodies to T. gondii was $86.2 \%$ and herd seroprevalences for species were $81.8 \%$ (9/11) in sheep, $75 \%(3 / 4)$ in goats and $86.7 \%(13 / 15)$ in cattle.

Significantly higher seroprevalence was observed in domestic ruminants (25.3\% of 482 animals tested) compared to wild ungulates (13.7\% of 1659) sampled in Córdoba Province $(P<0.001)$. The seropositivity was also significantly higher in sheep compared to the other species analysed $(P<$ $0.05)$. 
Risk factors associated to $T$. gondii infection in domestic ruminants were the species, presence of cats, feeding on ground, and feeding at stubble fields (Table 2). Significantly higher seroprevalence was found in sheep compared to the other domestic ruminant species $(P<0.05)$.

Seroprevalence in domestic ruminants from farms with presence of cats was $31.0 \%$ (109 of 352), while in the absence of cats, the seroprevalence was $10.0 \%$ (13 of 130). Herds in which food was provided directly on the ground showed significantly higher seroprevalence levels than those in which food was not provided on the ground $(32.7 \%$ of 153 versus $21.9 \%$ of 329 , respectively). The seroprevalence level in domestic ruminants fed at stubble fields was significantly higher compared to those that did not feed at stubble fields ( $42.6 \%$ of 216 samples versus $11.3 \%$ of 266 samples, respectively).

\section{Table 2}

Risk factors associated to Toxoplasma gondii seropositivity in domestic ruminant species in Southern Spain

\begin{tabular}{|l|l|l|l|l|l|l|}
\hline \multicolumn{1}{|c|}{ Variable } & Category & \multicolumn{1}{|c|}{$\boldsymbol{\beta}$} & \multicolumn{1}{|c|}{ Sig. } & OR & \multicolumn{2}{|c|}{$95 \%$ CI } \\
\hline \multirow{2}{*}{ Species } & Goat & $*$ & $*$ & $*$ & $*$ & $*$ \\
\hline & Cattle & 1.151 & 0.022 & 3.162 & 1.177 & 8.498 \\
\hline Sheep & 1.861 & $<0.001$ & 6.461 & 2.417 & 17.111 \\
\hline Presence of cat & No & $*$ & $*$ & $*$ & $*$ & $*$ \\
\hline Feeding on ground & Yes & 1.068 & 0.002 & 2.910 & 1.469 & 5.763 \\
\hline \multirow{2}{*}{ Feeding at stubble field } & Ne & $*$ & $*$ & $*$ & $*$ & $*$ \\
\hline & Yes & 0.59 & 0.018 & 1.803 & 1.105 & 2.943 \\
\hline
\end{tabular}

Asterisk indicates reference category

Antibodies against $T$. gondii were detected in $10.5 \%$ of the red deer $(95 \%$ CI $8.7-12.4 \%$ ), $15.6 \%$ of the fallow deer (95\% CI $11.5-19.8 \%$ ), $5.6 \%$ of 
the mouflons (95\% CI 2.5-8.6\%), 5.6\% of the Spanish ibexes (95\% CI 0.8 $-10.3 \%), 13.6 \%$ of the roe deer (95\% CI $0.0-28.0 \%)$ and in $18.6 \%$ of the wild boars (95\% CI 15.7-21.6\%) (Table 1). At least one seropositive animal was detected in $62(61.4 \%)$ of the 101 hunting areas sampled. Risk factors associated with $T$. gondii infection in wildlife in Córdoba Province were species, age and hunting season (Table 3). Significantly higher seroprevalences were observed in red deer, fallow deer and wild boar compared to mouflon. Prevalence of antibodies against $T$. gondii in wild ungulates was significantly higher in adults $(16.1 \%$ of 883$)$ compared to subadults (10.9\% of 495$)$ and yearlings (10.8\% of 241). Significant differences in the prevalence of levels of antibodies were observed among hunting seasons, being 2.3 to 2.6 times higher in hunting seasons from 2011 to 2012 and 2013 to 2014, compared to hunting season 2014 to 2015 (Table 3).

\section{Table 3}

Risk factors associated to Toxoplasma gondii seropositivity in wild ungulates species in Southern Spain

\begin{tabular}{|c|c|c|c|c|c|c|}
\hline Variable & Category & $\beta$ & Sig. & OR & \multicolumn{2}{|c|}{$95 \%$ CI } \\
\hline \multirow{4}{*}{ Species } & Mouflon & $*$ & $*$ & * & * & * \\
\hline & Red deer & 0.843 & 0.018 & 2.324 & 1.155 & 4.675 \\
\hline & Fallow deer & 1.335 & 0.001 & 3.801 & 1.760 & 8.212 \\
\hline & Wild boar & 1.559 & 0.000 & 4.756 & 2.388 & 9.471 \\
\hline \multirow{3}{*}{ Age } & Yearlings & $*$ & $*$ & $*$ & $*$ & $*$ \\
\hline & Subadults & -0.166 & 0.521 & 0.847 & 0.511 & 1.405 \\
\hline & Adults & 0.516 & 0.003 & 1.675 & 1.187 & 2.362 \\
\hline \multirow[t]{4}{*}{ Hunting season } & $2011-2012$ & 0.817 & 0.000 & 2.264 & 1.509 & 3.397 \\
\hline & $2012-2013$ & 0.944 & 0.002 & 2.570 & 1.418 & 4.659 \\
\hline & 2013-2014 & 0.839 & 0.000 & 2.313 & 1.497 & 3.575 \\
\hline & 2014-2015 & $*$ & * & $*$ & $*$ & * \\
\hline Asterisk indicat & ference cat & & & & & \\
\hline
\end{tabular}




\begin{tabular}{|l|c|c|c|c|c|c|}
\hline Variable & Category & $\boldsymbol{\beta}$ & Sig. & OR & \multicolumn{2}{|c|}{$\mathbf{9 5 \%}$ CI } \\
\hline & $2015-2016$ & 0.371 & 0.121 & 1.449 & 0.907 & 2.317 \\
\hline
\end{tabular}

\section{Discussion}

Toxoplasma gondii is present in many heterogeneous epidemiological scenarios. Although this parasite is distributed worldwide, the factors that determine its presence in animal populations are still poorly understood. The results obtained in the present study indicate that $T$. gondii infection is widespread in the studied area, but significant differences were observed in sheep compared to the other analysed domestic and wild species. Management, ecology and feeding behaviour are potential factors to explain the high $T$. gondii exposure in this species.

The main risk factors associated with $T$. gondii infection in domestic ruminants were the presence of cats, feeding on the ground and feeding at stubble fields. The presence of felines has been shown to be an important risk factor for infection in livestock and wildlife in several studies worldwide, including Spain (Dubey 2010; García-Bocanegra et al. 2010a; García et al. 2012). Only one previous study analysed the seroprevalence of T. gondii in domestic cats in the South of Spain (Millán et al. 2009) and reported antibodies in more than $50 \%$ of the 53 cats analysed. In regard to wild felines, García-Bocanegra et al. (2010b) reported widespread and continuous presence of the parasite with high seroprevalence $(62.8 \%$ of 129 ) in the critically endangered Iberian lynx (Lynx pardinus).

Interestingly, feeding on the ground and feeding at stubble fields increased the seroprevalence of $T$. gondii in domestic ruminants as indication of environmental contamination and an increased probability of ingestion of T. gondii oocysts in the soil and/or even in dry, hard cereal areas. Toxoplasma gondii oocysts remain infective in the environment for years (Dubey 2010). The risk factors identified in domestic ruminants in the present study are an indication of contact with oocysts and horizontal 
transmission as the main way of $T$. gondii transmission in Mediterranean ecosystems in Southern Spain.

Toxoplasmosis in sheep is a major cause of abortion, foetal malformations, pre-term deliveries and stillbirths and thus can result in severe economic losses (Dubey 2010). In Spain, previous studies showed that T. gondii is widely prevalent in sheep (Mainar et al. 1996; García-Bocanegra et al. 2013). Although in the present study seroprevalences in cattle and goats were significantly lower compared to sheep, higher seroprevalence levels were observed in both species in a study in the neighbouring province of Seville, Andalusia (García-Bocanegra et al. 2013). In that study, goats showed the lowest seroprevalence levels compared to sheep and cattle, which is in accordance with our observations in the present study. A low seropositivity was also found in goats $(2.8 \%)$ in central Spain (Mainar et al. 1996), while a high seroprevalence (48\%) was detected in this species in northwestern Spain (Díaz et al. 2016). However, the results from different studies in different locations are not strictly comparable because of different serological tests, cut-off values, and geographical and climatic differences. Furthermore, the seroprevalence obtained in goats in the present study should be interpreted with care because of the limited number of analysed samples.

The possibility of zoonotic diseases transmitted from large-game species to humans is of public health concern. In the present study, the prevalence of antibodies against $T$. gondii in wild ungulates ranged from 5.6 to $18.6 \%$, in similar levels to those observed in domestic ruminants, other than sheep. The highest seroprevalence was found in wild boars. Swine become infected with $T$. gondii through ingestion of food and water contaminated with sporulated oocysts, by ingestion of tissue cysts in infected animal tissues or congenitally (Dubey 2010). The seroprevalence observed in wild boars $(18.6 \%$ of 666$)$ in the present study is in accordance with that previously detected in Spain (23.8\% of 2881) (Calero-Bernal et al. 2016) and France (17.6\% of 148) (Richomme et al. 2009). However, other studies performed in this species in the Iberian Peninsula have reported a higher seropositivity to T. gondii (38.4\% of 507) (Gauss et al. 2005). 
The main risk factors associated with $T$. gondii infection in wild ungulates were age and hunting seasons. The higher seroprevalence in older animals reflects a cumulative likelihood for exposure to $T$. gondii and lifelong persistence of antibodies. The results are in accordance with that previously observed in wild and domestic species and suggested that horizontal transmission was the main route of infection in these species (Panadero et al. 2010; García-Bocanegra et al. 2013; Calero-Bernal et al. 2016). Significant decreasing seroprevalence levels were observed in the last sampled hunting seasons, which could be explained by the fact that those years have been the driest of the last decade in the area studied and a humid environment favours the persistence of infective $T$. gondii oocysts (Dubey 2010).

The FAO/WHO reported a global multi-criteria-based ranking of foodborne parasites with $T$. gondii in the top five of importance (FAO/WHO 2014). In addition, the EFSA (2007) recommended $T$. gondii monitoring of game species. In Andalusia, around 56,000 red deer and 43,000 wild boars are hunted every year (MAPAMA 2016). Based on the number of seropositive animals found in the present study, around 66 tons of meat and derived products from red deer and 60 tons of meat and derived products from wild boar could be contaminated by $T$. gondii. Of these, 51 tons of meat and derived products from red deer and wild boar is annually consumed as raw or undercooked food. Further studies are warranted to elucidate the $T$. gondii infection levels in meat and derived products from infected wild ungulates and the risk of transmission of this food-borne zoonotic disease.

\section{Acknowledgements}

The authors would like to give special thanks to the farmers and gamekeepers for their collaboration. This work was partially supported by projects AGL2013-49159-C2-2-R and INIA Grant FAU2008-00019-C0301 .

Compliance with ethical standards AQ6 
Animals were sampled during the hunting season under Spanish and EU legislation. No animals were specifically hunted for this study and ethical approval by an Institutional Animal Care and Use Committee was not deemed necessary.

AQ7

Conflict of interest The authors declare that they have no conflict of interest.

\section{References}

AQ8

Apollonio M, Andersen R, Putman R (2010) European ungulates and their management in the 21 st century. Cambridge University Press, Cambridge

Arenas-Montes A, García-Bocanegra I, Paniagua J, Franco JJ, Miró F, Fernández-Morente M, Carbonero A, Arenas A (2013) Blood sampling by puncture in the cavernous sinus from hunted wild boar. Eur J Wildl Res 59(2):299-303. https://doi.org/10.1007/s10344-013-0701-3

Calero-Bernal R, Pérez-Martín JE, Reina D, Serrano FJ, Frontera E, Fuentes I, Dubey JP (2016) Detection of zoonotic protozoa Toxoplasma gondii and Sarcocystis suihominis in wild boars from Spain. Zoonoses Public Health 63:346-350

Cook AJ, Gilbert RE, Buffolano W, Zufferey J, Petersen E, Jenum PA, Foulon W, Semprini AE, Dunn DT (2000) Sources of Toxoplasma infection in pregnant women: European multicentre case-control study. European Research Network on Congenital Toxoplasmosis. BMJ 321 (7254):142-157. https://doi.org/10.1136/bmj.321.7254.142

Díaz P, Cabanelas E, Díaz-Cao JM, Viña M, Béjar JP, Pérez-Creo A, Prieto A, López CM, Panadero R, Fernández G, Díez-Baños P, Morrondo P (2016) Seroprevalence of Toxoplasma gondii and Neospora 
caninum in goats from north-western Spain. Ann Agric Environ Med 23 (4):587-590. https://doi.org/10.5604/12321966.1226851

Dubey JP (2010) Toxoplasmosis of animals and humans. CRC Press, Boca Raton

Dubey JP, Desmonts G (1987) Serological responses of equids fed Toxoplasma gondii oocysts. Equine Vet J 19(4):337-339. https://doi.org/10.1111/j.2042-3306.1987.tb01426.x

EFSA (2007) Surveillance and monitoring of Toxoplasma in humans, food and animals. Scientific Opinion of the Panel on Biological Hazards. EFSA J 583:1-64

FAO/WHO [Food and Agriculture Organization of the United Nations/World Health Organization] (2014) Multicriteria-based ranking for risk management of food-borne parasites. Microbiological Risk Assessment Series 23:302

García G, Sotomaior C, do Nascimento AJ, Navarro IT, Soccol VT (2012) Toxoplasma gondii in goats from Curitiba, Paraná, Brazil: risks factors and epidemiology. Rev Bras Parasitol Vet 21(1):42-47. https://doi.org/10.1590/S1984-29612012000100009

García-Bocanegra I, Simon-Grifé M, Dubey JP, Casal J, Martín GE, Cabezón O, Perea A, Almería S (2010a) Seroprevalence and risk factors associated with Toxoplasma gondii in domestic pigs from Spain. Parasitol Int 59(3):421-426. https://doi.org/10.1016/j.parint.2010.06.001

García-Bocanegra I, Dubey JP, Martínez F, Vargas A, Cabezón O, Zorrilla I, Arenas A, Almería S (2010b) Factors affecting seroprevalence of Toxoplasma gondii in the endangered Iberian lynx (Lynx pardinus). Vet Parasitol 167(1):36-42. https://doi.org/10.1016/j.vetpar.2009.09.044 
García-Bocanegra I, Cabezón O, Hernández E, Martínez-Cruz MS, Martínez-Moreno Á, Martínez-Moreno J (2013) Toxoplasma gondii in ruminant species (cattle, sheep, and goats) from Southern Spain. J Parasitol 99(3):438-440. https://doi.org/10.1645/12-27.1

Gauss CB, Dubey JP, Vidal D, Ruiz F, Vicente J, Marco I, Lavin S, Gortázar C, Almería S (2005) Seroprevalence of Toxoplasma gondii in wild pigs (Sus scrofa) from Spain. Vet Parasitol 131(1-2):151-156. https://doi.org/10.1016/j.vetpar.2005.04.023

Gauss CB, Dubey JP, Vidal D, Cabezón O, Ruiz-Fons F, Vicente J, Marco I, Lavín S, Gortázar C, Almería S (2006) Prevalence of Toxoplasma gondii antibodies in red deer (Cervus elaphus) and other wild ruminants from Spain. Vet Parasitol 136(3-4):193-200. https://doi.org/10.1016/j.vetpar.2005.11.013

Hosmer DW, Lemeshow S (2000) Applied logistic regression. Wiley Press, New York. https://doi.org/10.1002/0471722146

Jiménez-Ruiz S, Arenas-Montes A, Cano-Terriza D, Paniagua J, Pujols J, Miró F, Fernández-Aguilar X, González MA, Franco JJ, GarcíaBocanegra I (2016) Blood extraction method by endocranial venous sinuses puncture in hunted wild ruminants. Eur J Wildl Res 62(6):775 -780. https://doi.org/10.1007/s10344-016-1056-3

Mainar RC, de la Cruz C, Asensio A, Domínguez L, Vázquez-Boland JA (1996) Prevalence of agglutinating antibodies to Toxoplasma gondii in small ruminants of the Madrid region, Spain, and identification of factors influencing seropositivity by multivariate analysis. Vet Res Commun 20(2):153-159. https://doi.org/10.1007/BF00385636

MAPAMA (2016) http://www.mapama.gob.es/es/biodiversidad/estadisticas/Est_Anual _Caza.aspx (accessed August 2017) 
Millán J, Candela MG, Palomares F, Cubero MJ, Rodríguez A, Barral M, de la Fuente J, Almería S, León-Vizcaíno L (2009) Disease threats to the endangered Iberian lynx (Lynx pardinus). Vet J 182(1):114-124. https://doi.org/10.1016/j.tvj1.2008.04.005

Montoya JG, Liesenfeld O (2004) Toxoplasmosis. Lancet 363 (9425):1965-1976. https://doi.org/10.1016/S0140-6736(04)16412-X

Panadero R, Painceira A, López C, Vázquez L, Paz A, Díaz P, Dacal V, Cienfuegos S, Fernández G, Lago N, Díez-Baños P, Morrondo P (2010) Seroprevalence of Toxoplasma gondii and Neospora caninum in wild and domestic ruminants sharing pastures in Galicia (Northwest Spain). Res Vet Sci 88(1):111-115. https://doi.org/10.1016/j.rvsc.2009.05.010

Richomme C, Aubert D, Gilot-Fromont E, Ajzenberg D, Mercier A, Ducrot C, Ferté H, Delorme D, Villena I (2009) Genetic characterization of Toxoplasma gondii from wild boar (Sus scrofa) in France. Vet Parasitol 164(2-4):296-300. https://doi.org/10.1016/j.vetpar.2009.06.014

Sáenz de Buruaga M, Lucio-Calero A, Purroy-Iraizoz FJ (2001) Reconocimiento de sexo y edad en especies cinegéticas. Edilesa, Leon

San Miguel JM, Gutiérrez-Expósito D, Aguado-Martínez A, GonzálezZotes E, Pereira-Bueno J, Gómez-Bautista M, Rubio P, Ortega-Mora LM, Collantes-Fernández E, Álvarez-García G (2016) Effect of different ecosystems and management practices on Toxoplasma gondii and Neospora caninum infections in wild ruminants in Spain. J Wildl Dis 52(2):293-300. https://doi.org/10.7589/2015-07-176

SSCCC - Spanish Superior Council of Chambers of Commerce (2009) Distribución comercial, estadísticas y estudios. Ministerio de Economía y Competitividad, Government of Spain. http:// www.comercio.gob.es (accessed August 2017) 